\title{
Drive-in steel storage racks II: Reliability-based design for forklift truck impact
}

\author{
Hao Zhang ${ }^{1}$ (A.M. ASCE), Benoit P. Gilbert ${ }^{2}$ \\ and Kim J. R. Rasmussen ${ }^{3}$ (M. ASCE)
}

\begin{abstract}
Steel drive-in racks are susceptible to structural failure due to accidental impact by 2 operating forklift trucks. Under impact, the upright bends and the supported pallets may 3 drop through the rack to cause structural collapse if the bay opening exceeds the pallet 4 bearing width. This drop-through limit state has not been considered in the existing rack 5 design standards. This paper proposes a simple equation to calculate the equivalent static 6 impact force based on recent tests and finite element analysis of drive-in racks (Gilbert and 7 Rasmussen, 2011). An impact load factor is developed on the basis of a structural reliability 8 assessment, taking into account the uncertain nature of the impact force, structural resistance 9 and models used in structural analysis. In design practice, the bay opening is determined 10 from factored impact loads, and is not to exceed specified limits.
\end{abstract}

\section{INTRODUCTION}

A general introduction to drive-in steel racks is given in the companion paper (Gilbert ${ }_{13}$ and Rasmussen, 2011). Drive-in racks are susceptible to structural failure due to accidental ${ }_{14}$ impact by the operating forklift trucks. The impact forces the bay to open by pushing on ${ }_{15}$ the upright. If the bowing of the impacted upright is sufficiently large, the pallets can drop ${ }_{16}$ through as shown in Fig. 1. This frequently causes local collapse or progressive collapse of ${ }_{17}$

\footnotetext{
${ }^{1}$ Lecturer, School of Civil Engineering, University of Sydney, NSW 2006, Australia. email: hao.zhang@sydney.edu.au

${ }^{2}$ Formerly, Phd Student in School of Civil Engineering, University of Sydney, NSW 2006, Australia. Present, Lecturer, School of Engineering, Griffith University, QLD 4222, Australia. email: b.gilbert@griffith.edu.au (corresponding author)

${ }^{3}$ Professor, School of Civil Engineering, University of Sydney, NSW 2006, Australia. email: kim.rasmussen@sydney.edu.au
} 
the whole rack, presenting a hazard to the workers and leading to financial losses due to downtime and lost goods. This mode of failure defines a limit state that forms the basis for evaluating the safety of drive-in racks under forklift truck impact. For selective racks, it is commonly believed that the most severe damages are induced by an impact of the rear counterweight of the forklift truck on the lowest part of the uprights (Ng et al., 2008; RMI, 1993). For drive-in racks, an impact by the rear counterweight of the forklift truck usually will not force the upright to deform enough to trigger the drop-through failure. For a pallet to drop through, the load has to be raised and it is the pallet load carried by the forklift truck that impacts the rack, as demonstrated in Fig. 1. Impacts may occur in the cross-aisle or down-aisle directions. The former case is not as critical as the later because of the presence of the bracing members in the cross-aisle direction. In the case of impact in the down-aisle direction, the driver misjudges the location of the forklift truck and starts turning before the pallet has cleared the rack. The forklift truck, by typically rotating about its front wheel axis, causes the pallet to impact with the front upright of the rack, as illustrated in Fig. 2.

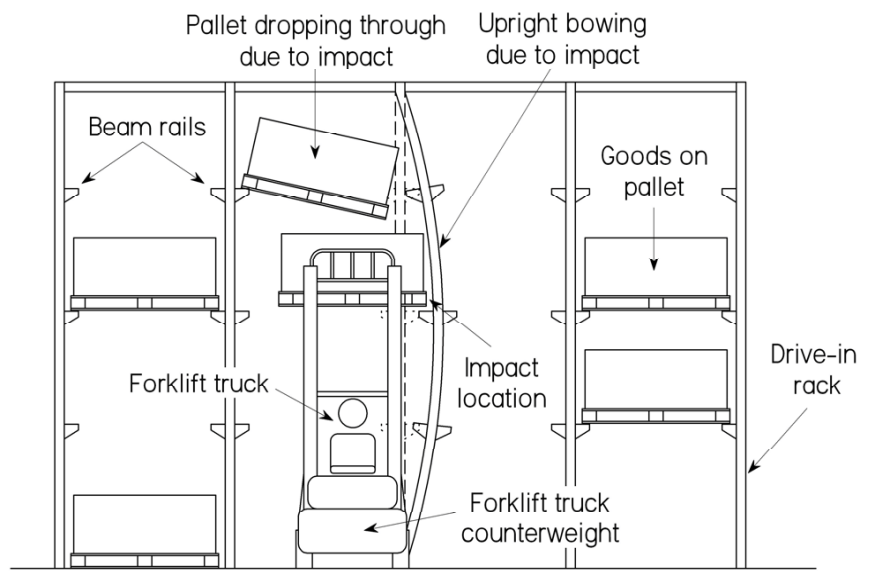

FIG. 1: Bowing of upright under forklift truck impact.

Most rack design guidelines recommend an allowance be made for impacts from the forklift truck. RMI (1993) gives qualitative guidelines by recommending designers to "safeguard racks against the consequences of minor collisions". However, a design impact load is not 


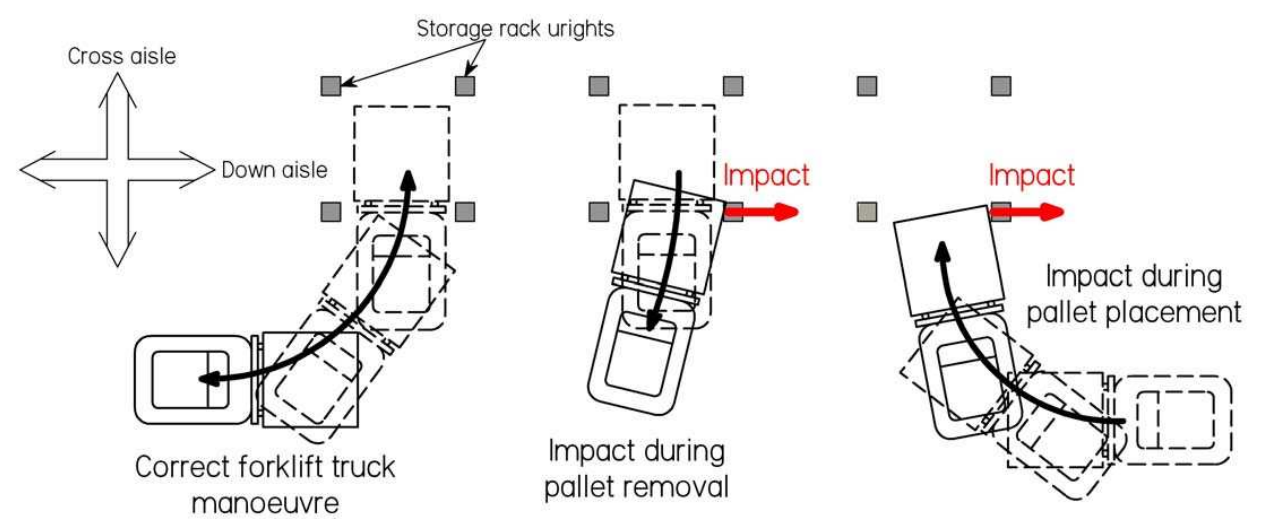

FIG. 2: Impact in the down-aisle direction.

specified. The Australian Standard AS4084 (1993) specifies a design impact load equivalent ${ }_{35}$ to the larger of the unit load/15 and $0.5 \mathrm{kN}$, applied at the most unfavorable location in 36 both cross-aisle and down-aisle directions. These guidelines are intended for use with selec- ${ }_{37}$ tive racks only. FEM 10.2.07 (2010) is a design guideline specifically for drive-in racks. It 38 specifies accidental loads of $1.25 \mathrm{kN}$ in the down-aisle direction and $2.5 \mathrm{kN}$ in the cross-aisle 39 direction. The impact force is applied up to $0.4 \mathrm{~m}$ above the floor, and should not cause 40 permanent structural damage to the rack.

The code-specified design impact forces are empirical in nature. A single constant impact 42 force is inconsistent from a uniform reliability viewpoint. Moreover, the drop-through limit 43 state has not been considered explicitly in the existing design standards. The companion ${ }_{44}^{4}$ paper (Gilbert and Rasmussen, 2011) describes static experimental tests and the development 45 of a finite element (FE) model for determining the behavior of drive-in steel storage racks. $\quad 46$ Further details are given in Gilbert and Rasmussen (2009a,b). This paper presents the ${ }_{47}$ development of a reliability-based checking procedure for the drop-through limit state. ${ }_{48}^{48}$

\section{STRUCTURAL RESPONSE UNDER IMPACT}

A limited number of investigations have been conducted for steel storage racks under 51 forklift truck impact. McConnel and Kelly (1983) investigated the progressive collapse of 52 
selective racks by notionally removing the bottom of an upright as a basis of damage assessment. The paper focuses on the nature of the collapse (confined or progressive) but not on the impact itself: the impact was simply assumed to be strong enough to remove the lowest section of one of the rack uprights. A similar "notional element removal" method was used by Bajoria (1986) to study the progressive collapse of selective racks. Ng et al. (2008) investigated the dynamic behavior of selective racks during and after impact. The impact force was evaluated using the momentum conservation principle. It was found that the maximum load that can be carried by a selective rack subjected to an impact can be predicted by a non-linear quasi-static pushover analysis. The scopes of these works, however, are limited to selective racks only, thus not applicable to drive-in racks.

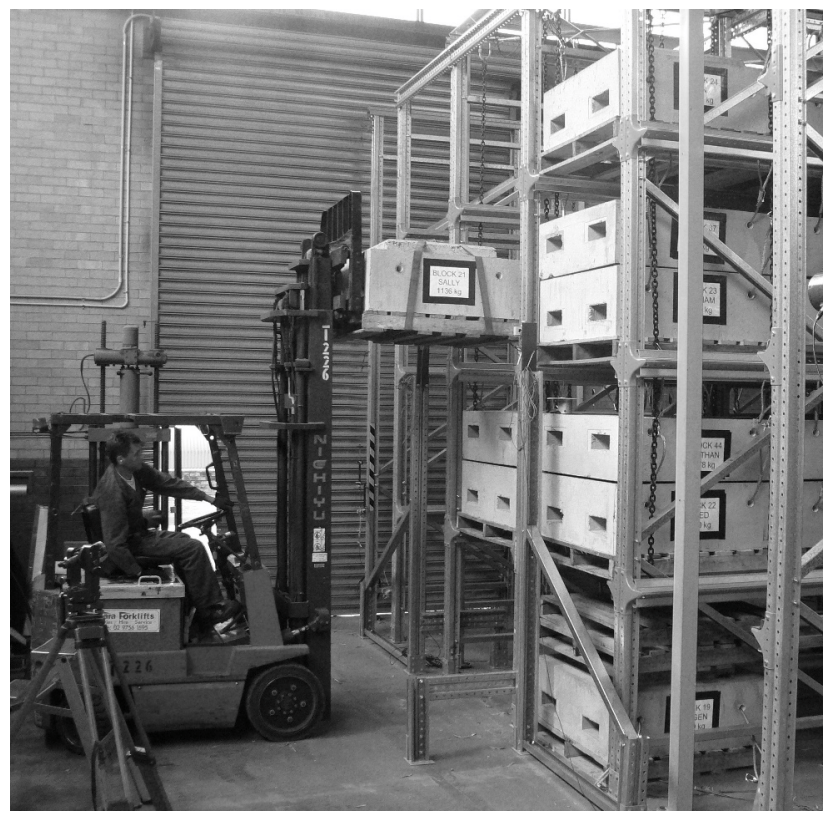

FIG. 3: A typical impact test.

Full-scale truck/rack impact tests have been conducted recently for a typical 4-bay, 4story, 4-pallet deep drive-in rack (Gilbert et al., 2009). The rack is the same as that tested in the companion paper, featuring a bay width of $1.475 \mathrm{~m}$ and a rack height of $5.0 \mathrm{~m}$. A loaded forklift truck was used to strike the rack as shown in Fig. 3. In the tests, the 


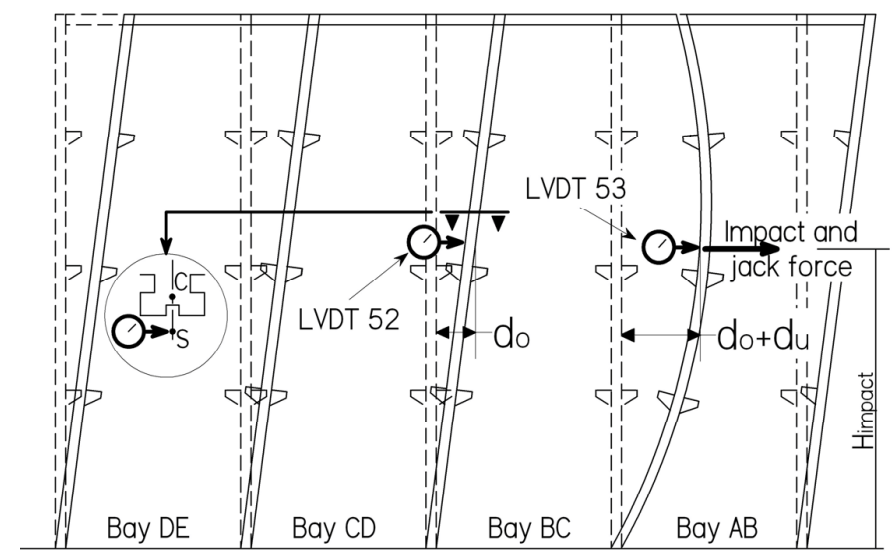

FIG. 4: LVDT locations.

forklift truck was first positioned in the bay and then reversed while turning about its front 67 wheel axis to impact the upright with the edge of the pallet. A total of 120 impact tests ${ }_{68}$ were conducted with different combinations of forklift truck load, rack loading pattern and 69 impact location. In each test, two Linear Variable Differential Transformers (LVDTs) were 70 placed at the shear center line of two adjacent uprights, as illustrated in Fig. 4. One LVDT 71 recorded the displacement at the impact point of the impacted upright. The other recorded 72 the displacement in the same direction at the same elevation of the adjacent upright. The 73 difference of the measurements of the two LVDTs represents the bay opening at the impact 74 point.

Figs. 5 and 6 plot the recorded LVDT displacements and bay opening against time from 76 a typical experimental test with a $1175 \mathrm{~kg}$ forklift truck load. Other tests showed similar 77 results. The structural response can be divided into four phases. In the first phase, the 78 upright being impacted experiences increasing lateral displacement. Other members of the 79 rack, however, essentially stay stationary. In the second phase the displacement at the 80 impact point continues to increase and reaches its peak. The bay opening, however, tends 81 to reduce because the adjacent uprights start to move in the same direction. At the end 82 of the second phase, the forklift truck and the rack lose contact. In the third and fourth 83 


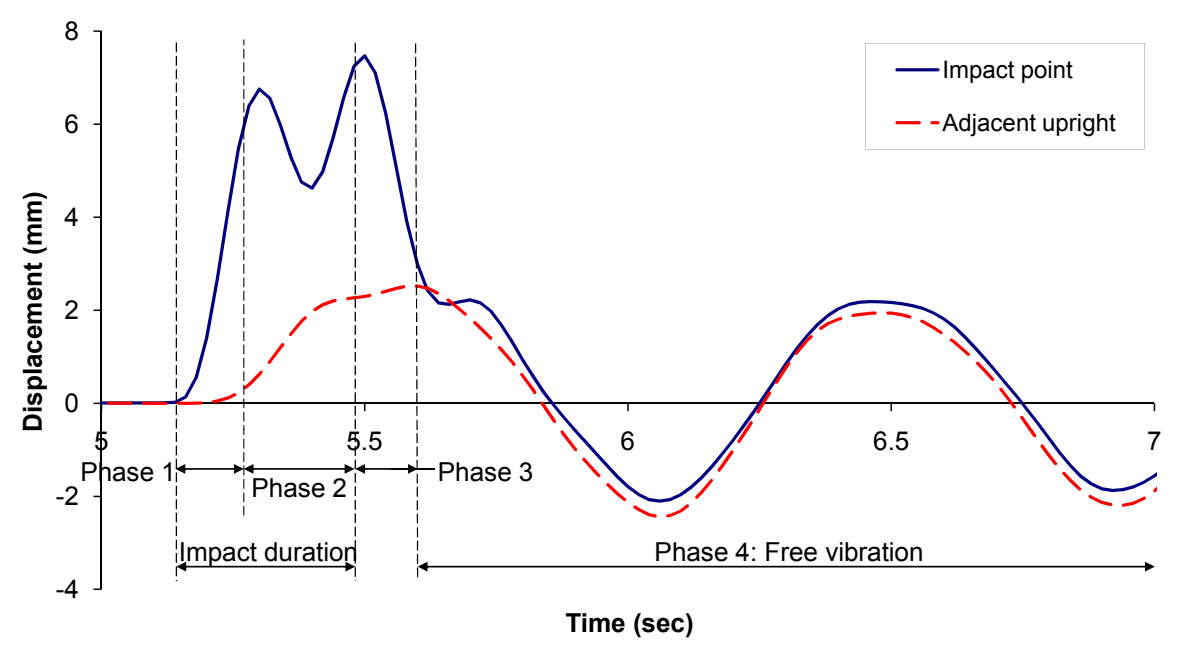

FIG. 5: Experimental result: displacements at impact point and adjacent upright.

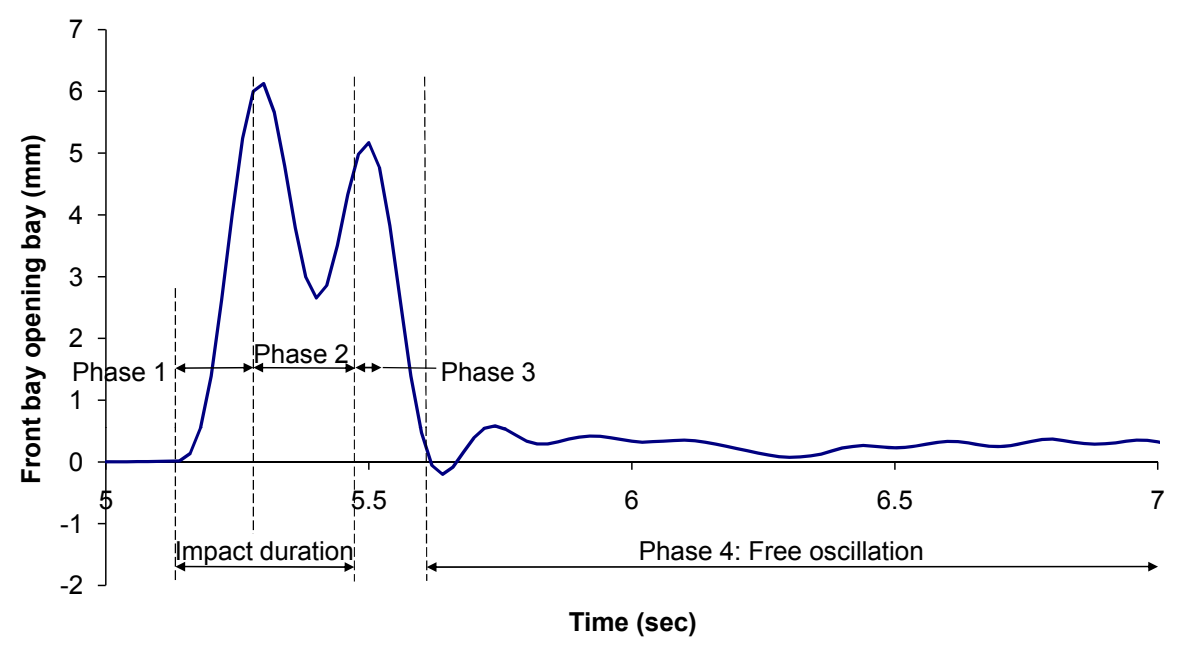

FIG. 6: Experimental result: bay opening.

(1)

7 (1)

phases, the rack experiences free vibration. In phase 3 the impacted upright bends back to its original position, closing the bay. In phase 4, the impacted upright essentially has the same displacement as the adjacent uprights, and the bay opening becomes negligible. Therefore, the maximum bay opening occurs at the end of the first phase. Details about the experimental test set-up and results are available in Gilbert et al. (2009). 


\section{Nonlinear dynamic analysis}

A three-dimensional dynamic FE model was developed to model the impact of forklift 90 truck and rack (Gilbert et al., 2009; Gilbert and Rasmussen, 2011). The FE model includes 91 geometric nonlinear effects, the semi-rigid nature of the base plate, semi-rigid portal beam- 92 to-upright connection details, upright warping torsion, member shear center eccentricity, 93 and nonlinear friction effect between the pallets and rail beams, as described in Gilbert and 94 Rasmussen (2011). Damping for steel rack structures is typically very small, and hence the 95 overall damping of the rack was ignored in the analyses. However, the friction between the 96 pallets and the rail beams generates non-linear frictional damping. This friction may be 97 significant and was modeled. Based on experimental frictional tests between the pallet and 98 the steel rail beam, a coefficient of friction of 0.3 was assumed in the analyses. Quantities of 99 interest, such as impact force versus time relationship, can be extracted from the FE results. $\quad 100$ Full details of the dynamic analysis can be found elsewhere (Gilbert et al., 2009).

Parametric studies were performed using the dynamic FE model to investigate the effect 102 on the bay opening of changing rack loading pattern, friction coefficient between the rail ${ }_{103}$ beams and the pallets, and impact location. Three loading patterns were investigated, 104 namely "single pallet load", "partially loaded" and "fully loaded". In the presence of friction 105 between the rail beams and the pallets and the consequential horizontal bracing effect of the ${ }_{106}$ pallets, it was found that more pallet loads generally result in higher impact forces but 107 smaller bay openings. When friction is ignored as currently practiced in industry, the single 108 pallet loading pattern results in the smallest rotational stiffness of the base plate, thus the ${ }_{109}$ largest bay opening. Therefore, whether or not to include the effect of the friction, the least ${ }_{110}$ favorable loading pattern is the single pallet loading, i.e., a single pallet located at the front ${ }_{111}$ of the rack. It was also found that impact at the first or second rail beam elevation tends to ${ }_{112}$ be more critical than those at higher elevations. When the impact occurs there will be no ${ }_{113}$ pallet located at the impact point, since otherwise the forklift cannot access that particular ${ }_{114}$ elevation. It is the pallets directly above or below the impact point that drop through (see ${ }_{115}$ 
Fig. 1). Thus, the bay opening should be checked at the elevations directly above/below the impact point. Fig. 7 demonstrates the most unfavorable loading pattern and impact location.

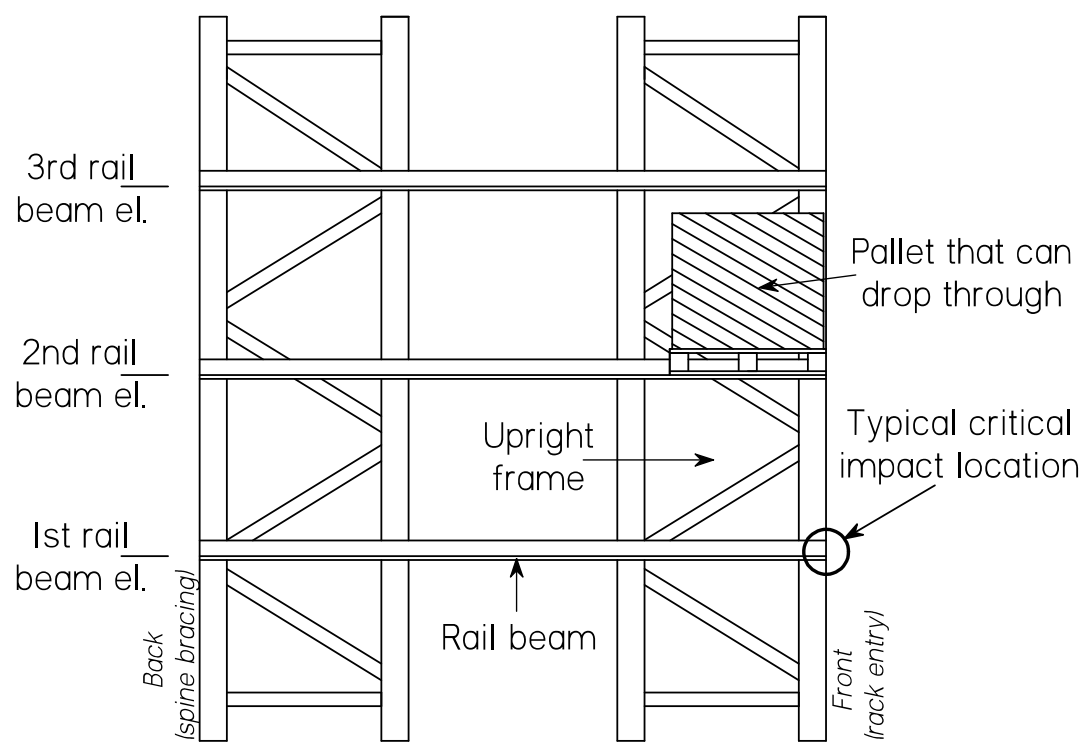

FIG. 7: The least favorable loading pattern: single pallet loading (side view).

\section{Equivalent static force for impact effect}

Although it would be possible for an engineer to perform the dynamic analysis presented above, it would be impractical to require this as part of a routine design procedure. Moreover, the safety check is based on the maximum value of the bay opening. From the structural design point of view, it is more appropriate to use an equivalent static force which produces the same (maximum) bay opening as produced by the dynamic impact force.

Experimental tests and numerical studies have shown that the impact force depends, among other factors, on forklift truck load, the stiffness properties of the upright being impacted, the impact elevation, and the rotational motion of the truck (measured by the rotational angle $\alpha$ as demonstrated in Fig. 8) (Gilbert et al., 2009). In order to account for these factors in deriving a simple equation for predicting the impact force, a total of 36 typical drive-in racks were analyzed using the dynamic FE model. The rack heights range from 3.775 


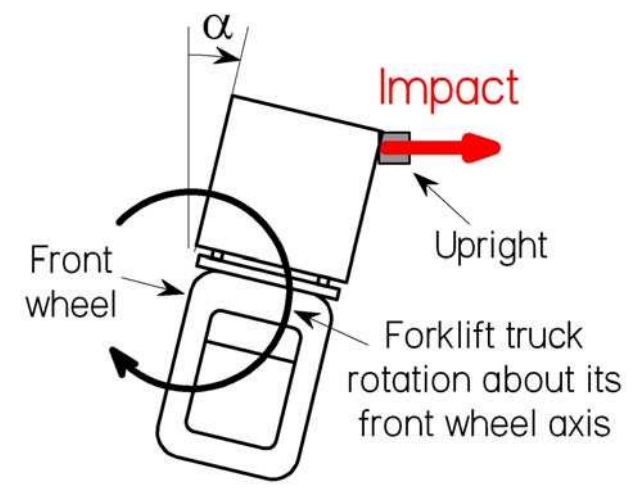

FIG. 8: Forklift truck body rotation $\alpha$.

to $8.775 \mathrm{~m}$ (2 to 6 stories), and the design load ranges from $430 \mathrm{~kg}$ to $1470 \mathrm{~kg}$ per pallet. ${ }^{131}$ These racks were identified to represent the current inventory of drive-in racks in Australia. ${ }_{132}$ For each rack, impacts were simulated at different rail beam elevations, assuming the single ${ }_{133}$ pallet load pattern. The impact forces were extracted from the FE results. Combining the ${ }_{134}$ 36 racks with different impact locations, a total of 100 representative impact scenarios were 135 made. Details about the rack configurations and impact scenarios can be found in Gilbert ${ }_{136}$ et al. (2009). Based on the study, a simple equation for calculating equivalent static impact ${ }_{137}$ force is proposed (Gilbert et al., 2009):

$$
F=4.94 \frac{\alpha L k_{1}}{1+0.1 \frac{k_{1}}{k_{2}}}
$$

where $F=$ impact force, $\alpha=$ angle of truck rotation as defined in Fig. 8 , and $L=$ vertical 139 distance from the bottom hinge of the mast of the forklift truck to the impact point. The ${ }_{140}$ two terms $k_{1}$ and $k_{2}$ are defined as

$$
\begin{aligned}
k_{1} & =\frac{E I H_{r}}{H_{i}^{2}\left(H_{r}-H_{i}\right)^{2}} \\
k_{2} & =\frac{w}{H_{i}+d_{c o g}}
\end{aligned}
$$




\section{RELIABILITY BASES FOR DESIGN FOR IMPACT EVENT}




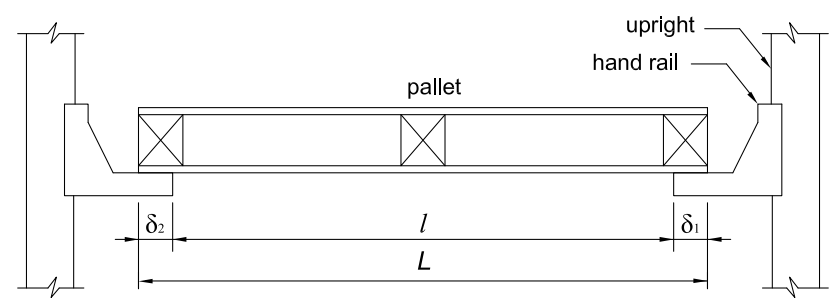

(a)

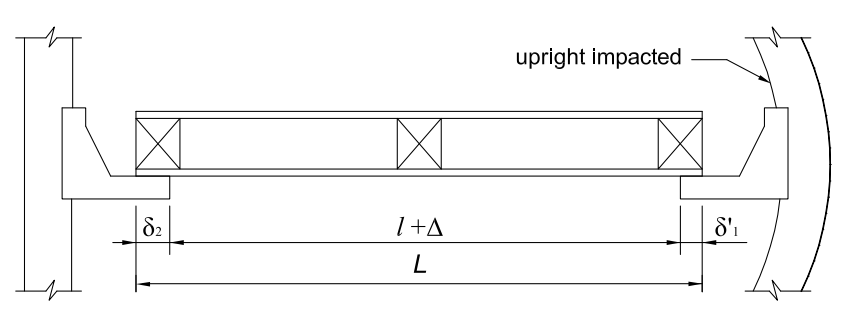

(b)

FIG. 10: Pallet bearing width: (a) under normal working condition; (b) under impact.

\section{Limit state function}

Consider a pallet in a typical drive-in rack as illustrated in Fig. 10a. It can be seen that ${ }_{158}$

$$
L=l+\delta_{1}+\delta_{2}
$$

in which $L=$ pallet width, $l=$ clear distance between the two beam rails, $\delta_{1}$ and $\delta_{2}$ are ${ }_{159}$ the bearing widths of the pallet on the two beam rails. Assume that the right upright is 160 impacted and pushed outwards as shown in Fig. 10b. Conservatively ignoring the friction 161 between the pallet and the beam rail, the pallet width $L$ becomes

$$
L=l+\Delta+\delta_{1}^{\prime}+\delta_{2}
$$

in which $\Delta=$ bay opening, and $\delta_{1}^{\prime}=$ new bearing width on the right beam rail. Note that ${ }_{163}$ the bearing width on the left beam rail, $\delta_{2}$, does not change as the left upright remains ${ }_{164}$ stationary in the most critical (i.e., the first) phase of the impact. From Eqs. (4) and (5), 165 one has

$$
\delta_{1}^{\prime}=\delta_{1}-\Delta
$$

The pallet will drop through if $\delta_{1}^{\prime} \leq 0$. Then, dropping the subscript " 1 " for simplicity, the ${ }_{167}$ system limit state function $g$ can be defined as

$$
g=\delta-\Delta .
$$


The drop-through failure occurs when $g \leq 0$.

The two terms $\delta$ and $\Delta$ in Eq. (7) are random variables while, for design practice, a deterministic format for Eq. (7) is needed. Although the drop-through limit state is similar to the ordinary serviceability limit state which is usually checked under unfactored loads, the consequence of the drop-through failure may be catastrophic, thus the limit state has the same nature as an ultimate limit state. Therefore, an impact load factor $\gamma$ (greater than 1 ) is introduced in the proposed design check. The proposed conformance check takes the form

$$
\gamma \Delta_{n} \leq \delta_{a}
$$

in which $\gamma \Delta_{n}$ represents the bay opening calculated with factored, design impact load and nominal structural properties, and $\delta_{a}$ is a (deterministic) allowable bay opening. The purpose of the load factor $\gamma$ is to take into account the uncertainties in the impact force, structural properties and models used in structural analysis, and to achieve a desired target of structural reliability. The determination of $\gamma$ will be discussed later in this paper.

\section{Conditional limit state probability}

The probability of structural failure developing from an accidental impact event can be written as (Ellingwood, 2007)

$$
P_{f}=P(g \leq 0 \mid \mathrm{I}) P(\mathrm{I})
$$

in which $P_{f}=$ probability of structural failure, $\mathrm{I}=$ event of accidental impact, $P(\mathrm{I})=$ probability of impact, and $P(g \leq 0 \mid \mathrm{I})=$ probability of structural failure (i.e., $g \leq 0)$ given that the impact occurs. $P(g \leq 0 \mid \mathrm{I})$ is a conditional probability, inasmuch as it is based on the occurrence of an impact event.

The risk of structural failure can be mitigated by strategies to reduce the incidence of impact, or to reduce its effect on structural performance through structural design if the impact does occur (Ellingwood, 2007). The occurrence of impact is an effect of human error, which may be controlled by vocational education and training, and organization and 
management measures such as appropriate regulation, installing impact guard rails or alarm 193 systems, etc. These nonstructural measures for reducing $P(\mathrm{I})$ are outside the scope of this 194 paper. From a structural design point of view, the focus is on controlling the conditional 195 failure probability $P(g \leq 0 \mid \mathrm{I})$, that is, to compensate for impact in structural design. $\quad 196$

\section{Reliability target}

Probabilistic limit state design is based on a target reliability (or acceptable probability 198 of failure) as a quantitative measure of structural safety (Melchers, 1999; Ellingwood, 2001). 199 Structures are deemed safe if the probability of failure, which is obtained through considering 200 uncertainties in loads, structural capacities and analysis models, is below an acceptable risk 201 level. The reliability is customarily expressed by the notion of a reliability index, $\beta$. The ${ }_{202}$ conditional failure probability relates the conditional reliability index $\beta$ through the equation ${ }_{203}$

$$
P(g \leq 0 \mid \mathrm{I})=\Phi(-\beta)
$$

in which $\Phi(\cdot)$ is the standard normal distribution function. From Eqs. (9) and (10), it follows 204

$$
\beta=-\Phi^{-1}\left[\frac{P_{f}}{P(\mathrm{I})}\right]
$$

In the current probability-based design specifications for steel structures (e.g., AISC 360- ${ }^{205}$ 05, 2005), the target reliability indices for various structural members under gravity loads 206 are about 2.5 to 3.0 for a service period of 50 years. On an annual basis, this corresponds ${ }_{207}$ to a failure probability of $1.24 \times 10^{-4}$ to $2.7 \times 10^{-5} / \mathrm{yr}$ (Ellingwood et al., 1980; Ellingwood, 208 2001). These reliability targets were obtained by calibrating to existing acceptable design 209 practice. Since drive-in rack structures are not designed for impact event in current practice, 210 the use of code calibration to quantify an appropriate reliability target is not possible in this ${ }_{211}^{21}$ study. For a steel drive-in rack, the structural members are generally designed at the code ${ }_{212}$ limit, and the system effect (i.e., capacity of load redistribution) is insignificant. Therefore, ${ }^{213}$ we assume that the acceptable failure probabilities for a racking system and a steel member ${ }_{214}$ 
are comparable. The consequences of collapse of a storage rack, compared with buildings and bridges, may be deemed as less severe by the public. Thus, the acceptable overall failure probability, $P_{f}$ for rack structures is assumed to be $2.0 \times 10^{-4} / \mathrm{yr}$, a value consistent with that of a typical steel member. This target is for the overall failure probability, rather than the conditional failure probability $P(g \leq 0 \mid \mathrm{I})$.

The frequency of occurrence of impact needs to be estimated to calculate the conditional failure probability from Eq. (11). Impact event may be modeled as occurring in time as a Poisson process, with a mean occurrence rate of $\nu$ (the average number of occurrence per unit time interval). Let $X$ denote the number of occurrences of impact in time interval $t$, then

$$
P(X=x)=\frac{(\nu t)^{x}}{x !} e^{-\nu t} \quad x=0,1,2, \ldots
$$

The probability of occurrence of (at least one) impact event during a period of time $t$ is given by

$$
P(\mathrm{I})=P(X \geq 1)=1-P(X=0) .
$$

For small occurrence rate, $P(\mathrm{I}) \approx \nu t$. There are little statistical data to define $\nu$. The mean incidence of vehicular collision with buildings in the USA is estimated of the order of $10^{-4} / \mathrm{bldg} / \mathrm{yr}$ (Ellingwood, 2007). The risk of accidental impact for storage racks may be significantly higher than this number. In deriving the impact load factor, a range of $\nu$ was considered, i.e., from $10^{-2}$ to $2 / \mathrm{rack} / \mathrm{yr}$.

\section{Statistical properties of impact force}

The impact force is characterized by high uncertainty. The uncertainty arises from two sources: the model uncertainty and the inherent randomness of the basic variables (e.g., the forklift truck body rotation). The model uncertainty can be regarded as a "correction factor", accounting for the discrepancy between the actual impact force and that predicted by Eq. (1). As discussed earlier in this paper, the model uncertainty associated with Eq. (1) is estimated as normally distributed with a mean of 1.0 and a COV of 0.145 . 
Among the physical factors affecting the impact force, the following variables are treated 239 as random: $w$ (the weight of the pallet load carried by the forklift truck), EI (the bending 240 stiffness of the impacted upright), and $\alpha$ (the maximum forklift truck body rotation during ${ }_{241}$ the impact). The probability distribution of the pallet load $w$ is assumed to be similar to 242 that of dead load, i.e., normally distributed with a mean-to-nominal value of 1.0 and a COV ${ }_{243}$ of 0.1 (Ellingwood et al., 1980). The bending stiffness of the upright is modeled by a normal ${ }^{244}$ distribution with a mean-to-nominal value of 1.0 and a COV of 0.08 (Ellingwood et al., 245 1980). The statistical data for the maximum forklift truck body rotation were collected 246 from a total of 116 experiments (Gilbert et al., 2009). Fig. 11 shows the histogram for the ${ }^{247}$ maximum truck body rotation, fitted to a Beta distribution with a mean of $0.023 \mathrm{rad}$ and 248 a COV of 0.46. In the present study, the nominal (design) value for $\alpha$ is taken as its mean ${ }^{249}$ value, i.e., $\alpha_{n}=0.023 \mathrm{rad}$. The statistics information for $w, E I$ and $\alpha$ are summarized in 250 Table 1.

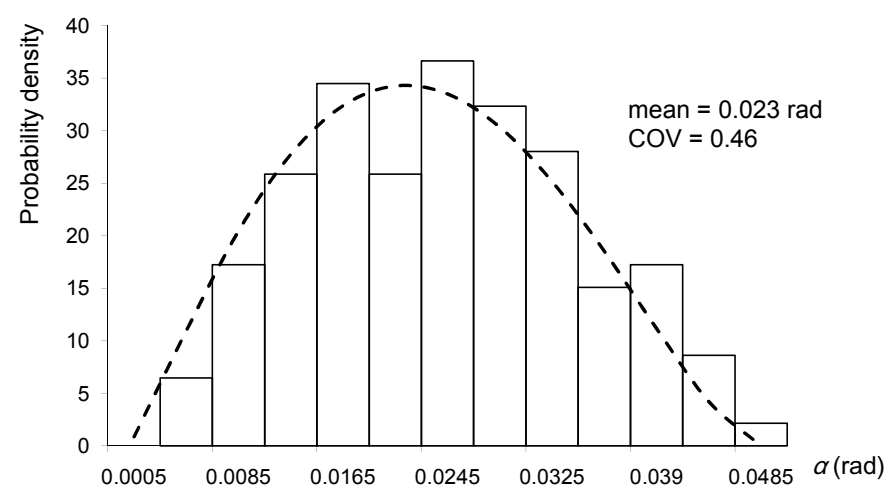

FIG. 11: Histogram for maximum truck body rotation (fitted to a Beta distribution).

With known statistical properties for the basic random variables and the model uncer- ${ }^{252}$ tainty, a simulation technique was used to study the probability distribution and statistics 253 for the impact force. A series of representative rack structures (Gilbert et al., 2009) were ${ }_{254}$ first chosen. For each particular structure, samples of the basic variables were generated 255 randomly according to their statistical distributions using the Latin Hypercube sampling 256 
TABLE 1: Statistical properties for the basic random variables.

\begin{tabular}{cccll}
\hline R.V. & mean/nominal & COV & Dist. & Reference \\
\hline$\alpha$ & 1.0 & 0.46 & Beta & Gilbert and Rasmussen (2009a) \\
$w$ & 1.0 & 0.10 & Normal & Ellingwood et al. (1980) \\
$E I$ & 1.0 & 0.08 & Normal & Ellingwood et al. (1980) \\
\hline
\end{tabular}

(LHS) method. LHS provides a more efficient sampling scheme than the direct Monte Carlo simulation, thus fewer samples are required to cover the probability space (Stein, 1987). The sampled basic variables, along with a randomly generated value of model uncertainty, were then used with Eq. (1) to compute the impact force. After a sufficient number (500) of simulations, the mean, mean-to-nominal ratio and COV for the impact force were determined. This simulation procedure was repeated for a series of representative racks. It was found that the mean-to-nominal value $F_{m} / F_{n}$ is about unit, and the $\mathrm{COV}, V_{F}$ is around 0.49 . A Beta distribution provides a good fit to the simulated impact forces. Clearly, the uncertainty in $\alpha$ is the dominant contributor to the overall variability in the impact force.

\section{Statistical properties of pallet bearing width}

There is an apparent lack of statistical data for the pallet bearing width in the literature. However, the bounds of the pallet bearing width can be readily obtained based on the manufacturing specifications. In typical Australian industry practice, the design bearing width for pallet is around $60 \mathrm{~mm}$. If the pallet is not positioned evenly between the two rails, the bearing width varies between $40 \mathrm{~mm}$ to $80 \mathrm{~mm}$. In general, let $\delta_{\mathrm{n}, \min }$ and $\delta_{\mathrm{n}, \max }$ denote the design minimum and maximum pallet bearing width. The pallet bearing width is assumed in this study to be uniformly distributed between these two extreme values. The assumption of uniform probability distribution is conservative because it possesses maximum uncertainty. 
The bay opening under the impact force can be calculated with sufficient accuracy by 277 using a first/second order elastic analysis. Since the second order effect is relatively insignif- ${ }^{278}$ icant when a rack structure is loaded with the single pallet loading configuration, the bay ${ }_{279}$ opening and impact force can be assumed as linearly related, i.e.,

$$
\Delta=f F
$$

where $f$ is the flexibility coefficient. The limit state function Eq. (7) thus can be expressed ${ }^{281}$ as

$$
g=\delta-f F .
$$

If a rack is designed at the limit, one has

$$
\delta_{a}=\gamma f_{n} F_{n}
$$

Using Eq. (16), (15) can be rewritten as

$$
g=f_{n} F_{n}\left(\gamma \frac{\delta}{\delta_{a}}-\frac{f}{f_{n}} \frac{F}{F_{n}}\right) .
$$

Eq. (17) implies that for a specified target reliability, the load factor $\gamma$ is dependent on the ${ }_{285}$ ratio of $\delta / \delta_{a}$. In the present study, the allowable bay opening $\delta_{a}$ is taken to be the design ${ }^{286}$ minimum pallet bearing width specified by the manufacturer, i.e.,

$$
\delta_{a} \equiv \delta_{\mathrm{n}, \min }
$$

Thus, the term $\delta / \delta_{a}$ is a uniform distribution with a lower bound of 1 and an upper bound ${ }_{288}$ of $\delta_{\mathrm{n}, \max } / \delta_{\mathrm{n}, \min }$. Three representative values, $\delta_{\mathrm{n}, \max } / \delta_{\mathrm{n}, \min }=1.5,2.0$ and 2.5 are considered 289 in determining the impact load factor. 
The variability in structural flexibility $f$ for a steel rigid frame under wind load has been studied by Galambos and Ellingwood (1986). The mean-to-nominal ratio $f_{m} / f_{n}$ was found to be around 1.0, and $V_{f}$ is mainly due to the variabilities in the bending stiffness of the column and is of the order of 0.08 . Values of $f_{m} / f_{n}$ and $V_{f}$ for a steel rack structure would not be dissimilar to those of a rigid frame. This paper thus adopts the values $f_{m} / f_{n}=1.0$ and $V_{f}=0.08$

With known statistics for $\delta, f$ and $F$, the load factor $\gamma$ for a prescribed conditional reliability index $\beta$ can be evaluated using standard reliability analysis methods such as the simulation method (Melchers, 1999). As discussed earlier in the paper, an appropriate target value for the overall failure probability $P_{f}$ is estimated as $2.0 \times 10^{-4} / \mathrm{yr}$. Under this assumption, Table 2 presents $P(\mathrm{I}), P(g \leq 0 \mid \mathrm{I})$, conditional reliability index $\beta$, and the impact load factor $\gamma$ for impact occurrence rate $\nu$ varying from $10^{-2}$ to $2 / \mathrm{rack} / \mathrm{yr}$. Three sets of impact load factors are listed in the table, with $\delta_{\mathrm{n}, \max } / \delta_{\mathrm{n}, \min }=1.5,2.0$ and 2.5 , respectively. As can be expected, for a given target reliability index the required impact load factor decreases as $\delta_{\mathrm{n}, \max } / \delta_{\mathrm{n}, \min }$ increases. However, the difference is not significant and the general trends are the same. This implies that the load factor $\gamma$ is relatively insensitive to $\delta_{\mathrm{n}, \max } / \delta_{\mathrm{n}, \min }$. The relationship between the load factor $\gamma$ and impact incidence $\nu$ is also graphically shown in Fig. 12 for the case where $\delta_{\mathrm{n}, \max } / \delta_{\mathrm{n}, \min }$ is equivalent to 2.0. It can be seen that the load factor increases as the impact occurrence rate $\nu$ increases. The curve, however, becomes essentially flat when $\nu$ exceeds $1 /$ yr. Although a designer can choose the impact load factor from Table 2 if the information on $\nu$ and $\delta_{\mathrm{n}, \max } / \delta_{\mathrm{n}, \min }$ is available, it is desirable in the practice to use a single load factor to simplify the design process. It may be observed that $\gamma$ falls within a range of 2.0 to 2.5 for $\nu$ varying from $10^{-1}$ to $1 / \mathrm{yr}$. A single factor, $\gamma=2.3$, appears to be satisfactory across a large range of impact occurrence rate, though it could be over-conservative if $\nu$ is less than or equal to $10^{-2} / \mathrm{yr}$.

\section{Design implications}

The proposed probability-based checking procedure can be summarized as follows: 
TABLE 2: Impact load factor $\gamma$

\begin{tabular}{llllrrr}
\hline$\nu(/ \mathrm{yr})$ & $P(\mathrm{I})$ & $P(g \leq 0 \mid \mathrm{I})$ & $\beta$ & $\gamma^{\mathrm{a}}$ & $\gamma^{\mathrm{b}}$ & $\gamma^{\mathrm{c}}$ \\
\hline $10^{-2}$ & 0.010 & $2.01 \times 10^{-2}$ & 2.05 & 1.77 & 1.61 & 1.52 \\
$10^{-1}$ & 0.095 & $2.10 \times 10^{-3}$ & 2.86 & 2.21 & 2.09 & 2.02 \\
0.5 & 0.393 & $5.08 \times 10^{-4}$ & 3.29 & 2.43 & 2.33 & 2.27 \\
1 & 0.632 & $3.16 \times 10^{-4}$ & 3.42 & 2.49 & 2.40 & 2.35 \\
2 & 0.865 & $2.31 \times 10^{-4}$ & 3.50 & 2.53 & 2.44 & 2.39 \\
\hline
\end{tabular}

Values are based on a target risk $P_{f}=2 \times 10^{-4} / \mathrm{yr}$.

${ }^{\mathrm{a}} \delta_{\mathrm{n}, \max } / \delta_{\mathrm{n}, \min }=1.5 .{ }^{\mathrm{b}} \delta_{\mathrm{n}, \max } / \delta_{\mathrm{n}, \min }=2.0 .{ }^{\mathrm{c}} \delta_{\mathrm{n}, \max } / \delta_{\mathrm{n}, \min }=2.5$.

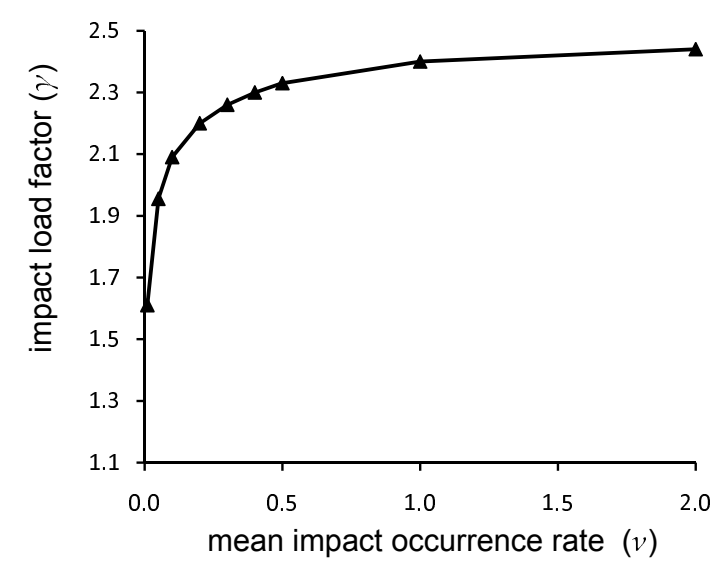

FIG. 12: Mean impact occurrence rate $\nu$ (per year) versus impact load factor $\gamma$ $\left(\delta_{\mathrm{n}, \max } / \delta_{\mathrm{n}, \min }=2.0\right)$.

1. Calculate the nominal impact load using Eq. (1) with a nominal truck body rotation 318 of $0.023 \mathrm{rad}$, i.e.,

$$
F_{n}=0.114 \frac{L k_{1}}{1+0.1 \frac{k_{1}}{k_{2}}} \approx \frac{L k_{1}}{10+\frac{k_{1}}{k_{2}}}
$$

where $k_{1}$ and $k_{2}$ are given by Eqs. $(2,3)$. The design impact load is obtained by 320 multiplying the nominal impact load $F_{n}$ by the load factor $\gamma=2.3$.

2. Apply the factored impact load assuming the least favorable loading pattern (single 322 pallet load pattern) and impact location (first or second rail beam elevation).

3. Calculate the nominal bay opening under the factored impact load, and check the 324 compliance with the minimum pallet bearing width. 


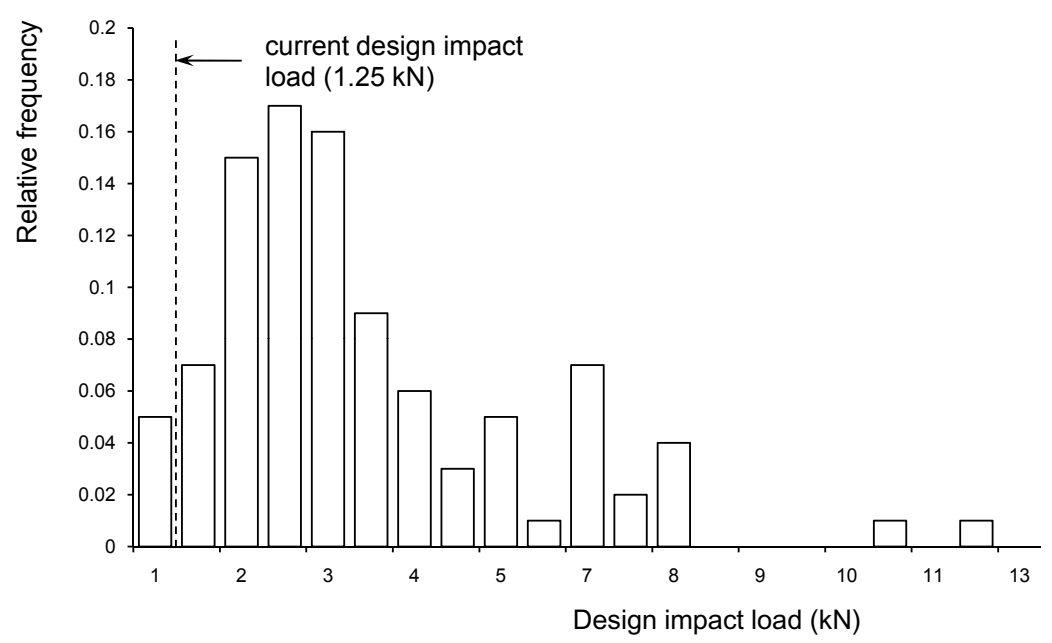

FIG. 13: Histogram for the design impact loads for 100 representative steel racks.

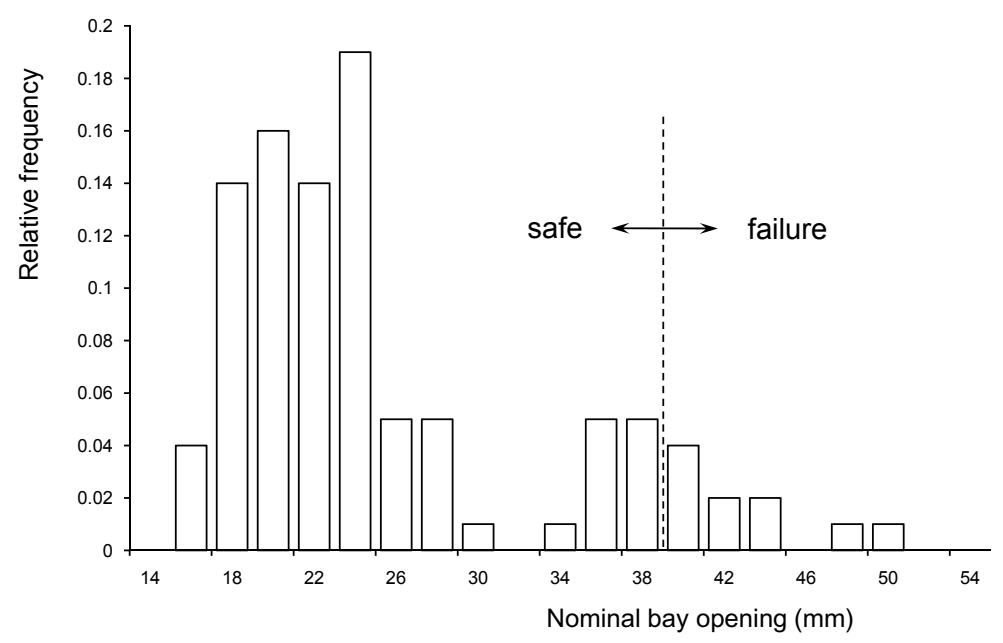

FIG. 14: Histogram for the bay openings for 100 representative steel racks under proposed design impact load.

The proposed checking procedure was applied to the series of representative steel racks (100 sample racks) identified in Gilbert et al. (2009). The pallet bearing width varies in the range of 40 to $80 \mathrm{~mm}$. Therefore, the allowable bay opening $\delta_{a}$ is taken to be the lower bound, i.e., $40 \mathrm{~mm}$. The impact loads and bay openings for the 100 sample racks were evaluated. Fig. 13 plots the histogram for the (factored) design impact loads, along with the existing design impact load of $1.25 \mathrm{kN}$ as specified in FEM 10.2.07 (2010). Note that 
the current $1.25 \mathrm{kN}$ impact load is to be applied up to $0.4 \mathrm{~m}$ above the floor, and is used to 332 check the strength limit state. It can be seen that in most (95\%) cases, the proposed design 333 impact load exceeds the current design value. This comparison suggests that current design 334 impact load of $1.25 \mathrm{kN}$ should not be used for checking the drop-through limit state. The 335 histogram for the nominal bay openings for the 100 sample racks under the design impact 336 loads is shown in Fig. 14. In approximately $10 \%$ of the cases, the nominal bay opening 337 exceeds the limit of $40 \mathrm{~mm}$ and those racks need to be strengthened in order to satisfy the 338 safety check.

\section{CONCLUSION}

This paper has described the development of a reliability-based safety checking procedure ${ }_{341}$ for steel drive-in racks under impact from forklift trucks. The limit state considered is the 342 drop-through failure, that is, the pallets fall from the rail beams due to excessive bowing of ${ }_{343}$ the impacted upright. The safety check requires the bay opening not to exceed the minimum 344 pallet bearing width specified by the manufacturer. An impact load factor was developed 345 using structural reliability theory, taking into account the uncertainties in the impact force, 346 structural properties and models used in structural analysis. The variability in the forklift 347 truck body rotation is found to be the dominant contributor to the uncertainty in the impact 348 force. The target value of overall structural reliability for a rack structure is assumed to be ${ }_{349}$ comparable to that of a typical steel member. The impact load factor is a function of the 350 occurrence rate of impact accident. However, for design purposes, a single impact load factor 351 of 2.3 appears to be satisfactory over a large range of impact occurrence rates. The research 352 also shows that the proposed impact load generally exceeds the existing design impact load. 353

\section{ACKNOWLEDGMENTS}

This research is supported by Australian Research Council under Discovery Project Grant 355 DP0559983. This support is gratefully acknowledged. The authors would like to thank Dr 356 Murray Clarke and Dr Lip Teh for their valuable comments. 


\section{REFERENCES}

AISC 360-05 (2005). Specification for structural steel buildings. American Institute of Steel Construction (AISC), Chicago, Illinois.

AS4084 (1993). Australian Standard AS4084-Steel Storage Racking. Standards Australia, Sydney, NSW 2001, Australia.

Bajoria, K. M. (1986). "Three dimensional progressive collapse of warehousing racking," PhD thesis, University of Cambridge.

Ellingwood, B. R. (2001). "Acceptable risk bases for design of structures." Prog. Struct. Engng. Mater., 3, 170-179.

Ellingwood, B. R. (2007). "Strategies for mitigating risk to buildings from abnormal load events." Int. J. Risk Assessment and Management, 7(6/7), 828-845.

Ellingwood, B. R., Galambos, T. V., MacGregor, J. G., and Cornell, C. A. (1980). "Development of a probability based load criterion for American National Standard A58." NBS special publication 577, National Bureau of Standards, Washington D.C.

FEM 10.2.07 (2010). The design of 'drive in and drive through racking' drive-in design code (version 0.12). Federation Europeenne de la Manutention, Brussels, Belgium.

Galambos, T. V. and Ellingwood, B. R. (1986). "Serviceability limit states: deflection." J. Struct. Engrg., ASCE, 112(1), 67-84.

Gilbert, B. P. and Rasmussen, K. J. R. (2009a). "Determination of accidental forklift truck impact forces on drive-in steel rack structures." Research Report No R902, Centre for Advanced Structural Engineering, School of Civil Engineering, University of Sydney.

Gilbert, B. P. and Rasmussen, K. J. R. (2009b). "Finite element modelling of steel drive-in rack structures." Research Report No R901, Centre for Advanced Structural Engineering, School of Civil Engineering, University of Sydney. 
Gilbert, B. P. and Rasmussen, K. J. R. (2011). "Drive-in steel storage racks I: Stiffness tests 382 and 3D load transfer mechanisms." J. Engrg. Mech., ASCE (in review). 383

Gilbert, B. P., Rasmussen, K. J. R., and Zhang, H. (2009). "Impact tests and parametric 384 impact studies on drive-in steel storage racks." Research Report No R903, Centre for 385 Advanced Structural Engineering, School of Civil Engineering, University of Sydney. 386

McConnel, R. E. and Kelly, S. J. (1983). "Structural aspects of the progressive collapse of ${ }^{387}$ warehouse racking." The Structural Engineer, 61A, 343-347.

Melchers, R. E. (1999). Structural reliability analysis and prediction. John Wiley \& Sons, 389 West Sussex, England, 2 edition.

Ng, A. L. Y., Beale, R. G., and Godley, M. H. R. (2008). "Dynamic analysis of rack 391 structures." 5th International Conference on Coupled Instabilities in Metal Structures, 392 K. J. R. Rasmussen and T. Wilkinson, eds., Sydney, Australia. 523-530.

RMI (1993). Specification for the design, testing and utilization of industrial steel storage 394 racks. Rack Manufacturers Institute, Charlotte, USA.

Stein, M. L. (1987). "Large sample properties of simulations using Latin Hypercube sam- 396 pling." Technometrics, 29(2), 143-151. 